\title{
Human immunodeficiency virus and hepatitis virus infection in correctional institutions in Africa: is this the neglected source of an epidemic?
}

Prisons form part of the criminal justice system and it is estimated that over 9 million people are in penal institutions worldwide. Overcrowding in prisons remains a concern in both developed and developing countries, and is a key causative factor for a myriad of other problems which ultimately turn these custodial settings into breeding grounds for infectious diseases such as AIDS, hepatitis, gonorrhoea, syphilis and tuberculosis. Compared to the general population, prisoners worldwide continue to demonstrate a significantly higher prevalence of human immunodeficiency virus (HIV), hepatitis B virus (HBV) and hepatitis $\mathrm{C}$ virus (HCV) infections (Weinbaum et al., 2005; Goyer, 2003; Allwright et al., 2000; Miranda et al., 2000; Singh et al., 1999). This phenomenon has been attributed to factors such as high-risk sexual behaviour before and during incarceration, intravenous drug use with sharing of syringes and drug paraphernalia, as well as tattooing among inmates (Allwright et al., 2000; Miranda et al., 2000; Butler et al., 1997).

In Africa, the median prison population rates range from 324/100 000 of the national population in Southern African countries to $52 / 100000$ in the West African nations (Walmsley, 2005). However, competing demands for available resources mean that budgetary allocations for prisons are limited, resulting in an inability to meet minimum basic international standards. In a recent United Nations report, overcrowding was apparent in 13 out of the 15 African countries surveyed, with many prisons operating at over $50 \%$ of their official capacity (Kibuka, 2001), and being unable to provide adequate arrangements to meet the special needs or prevent abuse of incarcerated women and juveniles. The prevalence of HIV infection in South African prisons is reported to be about $40 \%$, which is double the level in the general population (Goyer, 2003), but figures are lacking for inmates in many African countries. In addition, although $\mathrm{HBV}$ prevalence remains high with $\mathrm{HCV}$ infection now emerging as a public health concern on the continent (Koate et al., 2005; Lassey et al., 2004; Agwale et al., 2004; Kiire, 1996), we are still in the dark as to the prevalence of hepatitis in the high-risk prison population.

Adjei et al. (2006) in this issue of the journal take us inside three prisons in the West African country of Ghana to determine the prevalence of HIV, HBV, HCV and syphilis. The data provide tangible evidence to support anecdotal suggestions that an outbreak of these infections might be occurring in African prisons, affecting both inmates and prison staff. Furthermore, this high-risk group may represent the nucleus for the beginning of a HCV outbreak in the general population. The authors also highlight the problems of overcrowding, lack of access to medical facilities, and the absence of screening, immunization or health education programmes in these penal institutions. Their findings perhaps represent the state of affairs in penal institutions in many poor developing countries. There has been some debate recently about attention on chronic diseases versus infectious diseases in developing countries (Senok \& Botta, 2005; Yach et al., 2005; Strong et al., 2005). This work by Adjei et al. (2006) lends further credence to the concept that infectious diseases, including the HIV/AIDS epidemic, still pose considerable threats to Africa and gives an insight into the enormity of work that still needs to be done.

Although the World Health Organization's (WHO) guidelines for HIV/AIDS in prisons stipulate that all inmates have a right to equitable health care and that national AIDS programmes should be applied in jails (World Health Organization, 1993), this is rarely the case in many African countries.
Most inmates eventually get released and those infected represent a serious risk to their families and communities as they are reservoirs for further spread in the general population. In December 2005, at Africa's 14th International Conference on HIV/ AIDS, the executive director of The Joint United Nations Programme on HIV/AIDS (UNAIDS) stated that 'urgent and sustained action is needed at all levels to increase access to HIV prevention and treatment services across Africa'.

One of these levels would be to address the issue of HIV and other blood/sexually transmitted infections in the prison system. Firstly, we need more research, as the paucity of accurate data impedes proper appraisal of the impact of the prison population on the dynamics of the HIV/ AIDS epidemic in Africa. Women account for over $50 \%$ of people with HIV/AIDS in Africa and this gender disparity is even more marked among those aged 15-24 years (World Health Organization, 2004). Therefore, these studies must also investigate the specific characteristics and needs of incarcerated women and juveniles as well as young children who are living in prisons with their mothers. Secondly, there is a need to identify which policies and intervention programmes will work in African prisons in the face of limited resources and cultural norms. For example, condom distribution recommended by WHO and UNAIDS remains highly controversial due to moral and legal barriers in many countries (Zachariah et al., 2002; Anonymous, 1998). Outside prison walls, the refusal of condoms by men who consider their usage an affront to their manhood is well documented; in the prison environment the fear of intimidation and stigmatization makes it even more difficult for inmates to request them. In South Africa, the only African country where condoms and lubricant are provided for prisoners on request (since 1996), there is 
now a call to make them available in a more discreet manner. Education is a key component in a successful health intervention programme. The prison offers a controlled environment where health education and risk assessment can be offered to a traditionally hard to reach population. However, what works well on the outside may not necessarily apply behind prison walls. Therefore, the medium and content of such an intervention needs to take into account the prison 'subculture' that puts inmates at risk, as well as the deep-seated suspicion of authority and the low literacy rate in the prison population. Even with resource limitations, peer education and counselling programmes implemented by inmates (particularly gang leaders) and correctional officers are achievable, as shown by experiences in some African prison systems, and deserve serious consideration.

To make headway in addressing issues of prison health as public health issues, African nations would benefit from partnerships with non-governmental organizations, donor agencies and international bodies. More links between African researchers in correctional health issues and their counterparts in developed countries need to be forged to enhance capacity building and collaborative work. With such backing, effective prison health initiatives providing counselling, health education, confidential voluntary testing, care pathways, strategies for interrupting transmission as well as harm reduction can be developed and implemented. Such an approach would ultimately benefit the inmates, the correctional officers, families, communities and the general populace.

\section{A. C. Senok ${ }^{1}$ and G. A. Botta ${ }^{1,2}$}

${ }^{1}$ Department of Microbiology, Immunology and Infectious Diseases, College of Medicine and Medical
Sciences, Arabian Gulf University, PO Box 22979, Manama, Kingdom of Bahrain

${ }^{2}$ Udine Medical School, Department of Morphological and Medical Sciences, Pzle Kolbe 1, 33100, Udine, Italy

Correspondence: A. C. Senok (abiolacs@agu.edu.bh)

Adjei, A. A., Armah, H. B., Gbagbo, F., Ampofo, W. K., Quaye, I. K. E., Hesse, I. F. A. \& Mensah, G. (2006). Prevalence of human immunodeficiency virus, hepatitis $B$ virus, hepatitis $\mathrm{C}$ virus and syphilis among prison inmates and officers at Nsawam and Accra, Ghana. J Med Microbiol 55, 593-597.

Agwale, S. M., Tanimoto, L., Womack, C. \& 9 other authors (2004). Prevalence of HCV coinfection in HIV-infected individuals in Nigeria and characterization of HCV genotypes. J Clin Virol 31 (Suppl. 1), S3-S6.

Allwright, S., Bradley, F., Long, J., Barry, J., Thornton, L. \& Parry, J. V. (2000). Prevalence of antibodies to hepatitis B, hepatitis C, and HIV and risk factors in Irish prisoners: results of a national cross sectional survey. BMJ 321, 78-82.

Anonymous (1998). AIDS in prisons - good intentions, harsh realities in Africa's penitentiaries. AIDS Anal Afr 8, 12.

Butler, T. G., Dolan, K. A., Ferson, M. J., McGuinness, L. M., Brown, P. R. \& Robertson, P. W. (1997). Hepatitis B and C in New South Wales prisons: prevalence and risk factors. Med J Aust 166, 127-130.

Goyer, K. (2003). HIV/AIDS in Prison: Problems, Policies and Potential. Institute for Security Studies Monograph 79. http:// www.iss.co.za/Pubs/Monographs/No79/ Content.html (last accessed 20th January 2006).

Kibuka, E. (2001). Prisons in Africa: the United Nations Programme Network Institutes Technical Assistance Workshop, Vienna, Austria. http://www.unicri.it/wwk/related/pni/docs/ 2001/kibuka.pdf (last accessed 20th January 2006)

Kiire, C. F. (1996). The epidemiology and prophylaxis of hepatitis B in sub-Saharan Africa: a view from tropical and subtropical Africa. Gut 38 (Suppl. 2), S5-S12.
Koate, B. B., Buseri, F. I. \& Jeremiah, Z. A. (2005). Seroprevalence of hepatitis $C$ virus among blood donors in Rivers State, Nigeria. Transfus Med 15, 449-451.

Lassey, A. T., Damale, N. K., Bekoe, V. \& Klufio, C. A. (2004). Hepatitis C virus seroprevalence among mothers delivering at the Korle-Bu Teaching Hospital, Ghana. East Afr Med J 81, 198-201.

Miranda, A. E., Vargas, P. M., St Louis, M. E. \& Viana, M. C. (2000). Sexually transmitted diseases among female prisoners in Brazil: prevalence and risk factors. Sex Transm Dis 27, 491-495.

Senok, A. C. \& Botta, G. A. (2005). Chronic versus acute diseases. Science 309, 380-381.

Singh, S., Prasad, R. \& Mohanty, A. (1999). High prevalence of sexually transmitted and blood-borne infections amongst the inmates of a district jail in Northern India. Int J STD AIDS 10, $475-478$

Strong, K., Mathers, C., Leeder, S. \& Beaglehole, R. (2005). Preventing chronic diseases: how many lives can we save? Lancet 366, 1578-1582.

Walmsley, R. (2005). World Prison Population List, 6th edn, pp. 1-6. Kings College London: International Center for Prison Studies.

Weinbaum, C. M., Sabin, K. M. \& Santibanez, S. S. (2005). Hepatitis B, hepatitis $C$, and HIV in correctional populations: a review of epidemiology and prevention. AIDS 19

(Suppl. 3), S41-S46.

World Health Organization (1993). Global Programme on AIDS: WHO Guidelines on HIV Infection and AIDS in Prisons. WHO/GPA/DIR/ 93.3. Geneva: World Health Organization.

World Health Organization (2004). The World Health Report 2004 - Changing History. http:// www.who.int/whr/2004/en/ (last accessed 20th January 2006).

Yach, D., Leeder, S. R., Bell, J. \& Kistnasamy, B. (2005). Global chronic diseases. Science 307, 317.

Zachariah, R., Harries, A. D., Chantulo, A. S., Yadidi, A. E., Nkhoma, W. \& Maganga, O. (2002). Sexually transmitted infections among prison inmates in a rural district of Malawi. Trans $R$ Soc Trop Med Hyg 96, 617-619. 